\title{
An improved portfolio optimization model for oil and gas investment selection
}

\author{
Xue Qing ${ }^{1}$, Wang Zhen ${ }^{2 *}$, Liu Sijing ${ }^{1}$ and Zhao Dong ${ }^{3}$ \\ ${ }^{1}$ School of Business Administration, China University of Petroleum, Beijing 102249, China \\ ${ }^{2}$ Academy of Chinese Energy Strategy, China University of Petroleum, Beijing 102249, China \\ ${ }^{3}$ China National Oil and Gas Exploration and Development Corporation, Beijing 100034, China \\ (C) China University of Petroleum (Beijing) and Springer-Verlag Berlin Heidelberg 2014
}

\begin{abstract}
For oil company decision-makers, the principal concern is how to allocate their limited resources into the most valuable opportunities. Recently a new management philosophy, "Beyond NPV", has received more and more international attention. Economists and senior executives are seeking effective alternative analysis approaches for traditional technical and economic evaluation methods. The improved portfolio optimization model presented in this article represents an applicable technique beyond NPV for doing capital budgeting. In this proposed model, not only can oil company executives achieve trade-offs between returns and risks to their risk tolerance, but they can also employ an "operational premium" to distinguish their ability to improve the performance of the underlying projects. A simulation study based on 19 overseas upstream assets owned by a large oil company in China is conducted to compare optimized utility with non-optimized utility. The simulation results show that the petroleum optimization model including "operational premium" is more in line with the rational investors' demand.
\end{abstract}

Key words: Portfolio optimization, capital budgeting, operational premium; utility theory, risk tolerance

\section{Introduction}

The prominent question for decision-makers in petroleum companies is how to allocate their capital reasonably to the most valuable investment opportunities as to maximize their utility under a certain budget. Many companies employ Net Present Value (NPV) to evaluate Exploration and Production (E \& P) projects to empower better investment decisions. But the optimal selection of one single project may not be the optimal allocation that can realize the maximum return with the minimum risk for the company as a whole. Despite NPV remaining a critical criterion for most capital allocating process, difficulties arise within NPV analysis when justifying projects with longer-term, huge hidden internal costs and investors' various risk appetites. For investment decisions, risk and economic benefit are equally important. The volatilities of oil price, capital expense (Capex) and operating expense (Opex) would compound the complexity of upstream project selection. Therefore, petroleum company executives are moving on from deterministic NPV analysis to "beyond NPV" in their business planning analysis. "Beyond NPV" was formally emphasized by petroleum economists from SPE in 2012 ${ }^{1}$. Within the concept of "Beyond NPV", the integration of key performance indicators and uncertainties is strongly emphasized. Those uncertainties, rising from

*Corresponding author. email: wangzhen@cup.edu.cn

Received June 17, 2013 options, side effects on stakeholders' benefits, environmental issues, and risk preferences of decision-makers, provide significant growth contribution to investment risks (Ward and Ryals, 2001; Xu, 2013; Shu et al, 2013; Jordanger and Klakegg, 2013). Evans et al (2006) argued that, to meet sustainable development criteria, the industry need to adopt a broader range of valuation approaches besides NPV analysis. One of those alternative approaches is to employ the portfolio optimization method in terms of return to risk.

Portfolio theory was firstly put forward by Markowitz (1952). The portfolio theory proposes that a portfolio can be characterized by two indicators: the expected return of the portfolio and the variance of the expected return. The target of portfolio optimization is to minimize the variance for a given expected return or maximize the expected return for a given risk (Markowitz, 1952). This theory assumes a perfect market and that the investor's utility function of portfolio return is quadratic. Using variance as an indicator of risk can penalize both negative deviation and positive deviation from average. Markowitz revised the optimization model and proposed two new portfolio risk indicators: the below-mean semi variance and the below-target semi variance (Markowitz, 1959). Markowitz portfolio theory is supported by Fisher's

\footnotetext{
1 "Beyond NPV" was the theme of SPE Applied Technology Workshop "Petroleum Economics: Beyond NPV", Dubai, UAE, 26-28 March 2012.
} 
separation theorem. The Fisher separation theorem proposes that the security portfolio optimization model doesn't need to include individual risk preference because of the underlying hypothesis of risk-free and identical borrowing-lending interest rates that investors can take advantage of frictionless transactions to achieve the optimal state (Fisher, 1906; Tobin, 2005). Thus, the target of "expected return maximization" becomes equivalent to the target of "expected utility maximization" if we ignore investors' risk preferences and the forms of their utility functions. Therefore, the portfolio optimization theory proposed by Markowitz (1952) uses "expected return maximization" instead of "expected utility maximization".

Many industry sectors, such as aerospace, cogeneration and electricity generation, have employed the portfolio selection approach as an integral part of strategic planning to reduce exposure to fossil fuel price fluctuation (Huanga and Wub, 2008; Zhu and Fan, 2010; Locatelli and Mancini, 2011; Vithayasrichareon and MacGill, 2012; Guerrero-Lemus et al, 2012; Arnesano et al, 2012). Since investments in the exploitation of hydrocarbons involve a high degree of risk as the value of candidate projects can be of very different nature and scope and fluctuate dramatically with the key value drivers, petroleum companies are constantly faced with investment decisions in multiple projects (Park et al, 2009; Zhang, 2010; Jafarizadeh, 2010; Zhang and Wang, 2011; Liu et al, 2012). Although literature has shown that the mean-variance method is the simplest and most effective approach available for asset selection (Quiek, 1982; Quieu and Buek, 1983; Lima et al, 2005; Guo, 2007; Wang and Wang, 2008; Deng and Xu, 2009; Zhao, 2010; Jafarizadeh, 2010; Cartwright, 2011; Willigers et al, 2011; Westner and Madlener, 2011), oil companies in China rarely implement mean-variance portfolio management in practice. The application of modern portfolio theory in petroleum industry stagnates in China, technically due to the lack of reliable and adequate data on comparable candidate projects. Another vital concern in the application of modern portfolio theory in the petroleum industry will be the difference between the oil industry and the securities market, manifesting chiefly in five aspects: type of uncertainties, risk indicators, market characteristics, time periods and the effect of budget constraints (Orman and Duggan, 1999; Walls and Dyer, 1996; Walls, 2004; Ball and Savage, 1999; Hayashib et al, 2010; Egozcue et al, 2011; Sáncheza and Al-Harthy, 2011).

Considering these differences mentioned above, there are two main challenges that call for further theoretical evidence for its practical use: The first notable challenge is that the market of $\mathrm{O} \& \mathrm{G}$ asset merger and acquisition is frictional. We cannot find any risk-free candidate $\mathrm{E} \& \mathrm{P}$ project similar to the risk-free security. Under the premise of no arbitration and a ubiquitously risk-averse policy among oil and gas industry decision-makers, the principle of "Expected Utility-Variance" is more fitted in the petroleum market than the "Expected Return-Variance" principle (Cozzolino, 1977; 1979; Mansoor, 2007; Lasdon et al, 2007; Erdogan and Mudford, 2001; Rahmawatia et al, 2012). Besides, there is no short and long mechanism in oil \& gas transaction, and investor's equity share can only be within the range from 0 to $100 \%$.
Therefore, expected return maximization is not a substitute for the goal of expected utility maximization. The second significant challenge is that the participants in petroleum markets have the ability to improve the performance of their portfolios instead of just keeping the portfolios and waiting for their prices to rise, meaning that those investors also act as project operators. As for the first challenge, Cozzolino (1977, 1979) made his contribution by using expected utility criteria to replace expected return criteria. But as for the second challenge, no study is aimed at the effect of international oil companies' dual identity in asset management. To conquer the second challenge, this paper will explore a real asset portfolio optimization model by taking investors' dual identities into consideration.

\section{Capital budgeters and operational premium}

Oil company executives who make investment and project selection decisions are not like individual investors in the stock market. They are allocating capital to the best projects. Not only do executives care about the assessment and evaluation results given by professional investment advisors, such as Goldman Sachs and Morgan Stanley, but they also want to develop insights into the most operational potential among these candidate $\mathrm{E} \& \mathrm{P}$ projects because projects with operational potential can provide significant growth contribution to the projects' underlying value. To distinguish oil company executives from security investors, we call the latter "professional investors", and the former "capital budgeters", who can create added value by using their own technical skills, production experience, financial strength, risk management and control systems. We name the added value part "operational premium". Based on research into operating behaviors of oil companies, we find that the degree of operational premium is mainly affected by two factors: one is the operating efficiency of a certain investor; and the other is the degree of investor's control ability on the project, namely, ownership interest.

\section{1) Operating efficiency}

Measurement of operating efficiency can be considered from many aspects, including the input-output ratio, social status, staff development, social welfare contribution and $R \& D$ reserves. The most easily quantifiable factor is inputoutput ratio - the return on investment ratio a project will get. This paper chooses the input-output ratio to measure the operating efficiency.

\section{2) Ownership interest}

In Markowitz's portfolio theory, return on investment is an exogenous variable and investors are all price takers, so the ownership proportion of each asset will not impact the underlying yields. This theory is reasonable for most professional investors. But in the case of capital budgeters, like international oil companies, the ownership interest percentage will impact the operating efficiency to different degrees. Generally speaking, the greater proportion the investor's equity account for in an oil \& gas asset, the closer the asset's output function will get to that under the investor's full control. 
Suppose a capital budgeter has a operating efficiency of $e_{0}$ in an exsiting project when he has $0 \%$ ownership interest and an achievable efficiency of $e_{1}$ in that project when he has $100 \%$ ownership interest. When he changes the ownership interest to $w$, then the efficiency should be a function of $w$ and the corresponding operating efficiency should located between $e_{0}$ and $e_{1}$. According to real oil companies' management experience, the growth rate of operating efficiency is accelerated with the increase of the working interest, so operating efficiency can be expressed in a nonlinear form of $w$. Fig. 1 shows the convex property of operating efficiency.

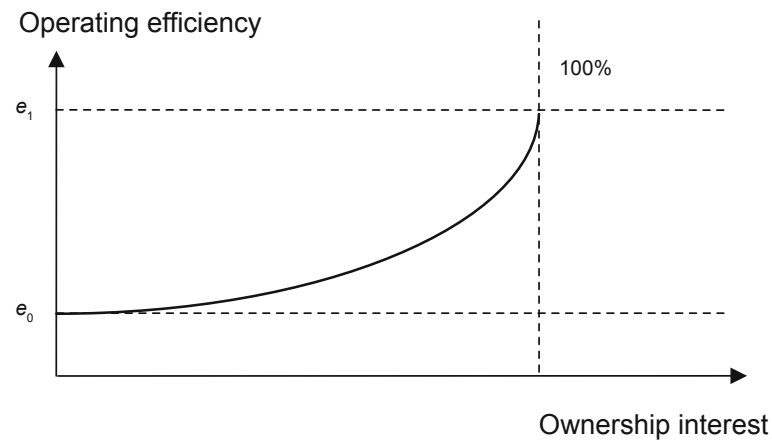

Fig. 1 Influence of ownership interest on operating efficiency

The convex ownership-efficiency line describes the nonlinear relationship between control power and the operating efficiency that a capital budgeter can achieve (Fig. 1). $e_{0}$ is the initial operating efficiency when a capital budgeter owns $0 \%$ equity share of the candidate asset. The maximum efficiency will be $e_{1}$, realized when the ownership increases to $100 \%$. The convexity between ownership interest and operating efficiency is matched with the underlying assumption that the control power of majority shareholders and minority shareholders on the same candidate project is not in accordance with the proportion of equity allocation respectively. In most cases, the majority shareholders have strong corporate governance, causing the "one share jumbo" phenomenon. Thus, the nonlinear efficiency function can be expressed in the form of $w^{a}$ for simplicity, where $a$ indicates how much the ownership interest of the underlying asset affect the elasticity of output efficiency. If $a$ is greater than 1, it denotes that the operating efficiency model is closer to the scenario of "one share jumbo". If $a$ is less than 1 , it represents that the minority shareholders may have more control than their equity allocation.

\section{Model design}

We set expected utility maximization as the goal of portfolio optimization given a specific level of risk and certain budget constraints. The criterion of maximizing expected utility offers a feasible way for asset selection under uncertainty, making it possible to distinguish diversified investment strategies made by different international oil companies at various risk-averse levels. Assume the utility function of a capital budgeter is a negative exponential expression of the total wealth $x$ such that:

$$
u(x)=-e^{-x / R T}
$$

where $x$, the total wealth, is given by $\left(\sum\left(w \times n p v_{i}\right)\right)$, namely the anticipated value of a project, and $R T$ is the risk tolerance of the investor. $u(x)$ is a dimensionless variable.

Suppose an original candidate portfolio $\Phi$ formed by upstream under-development projects and those projects are initially owned by professional investors. $\Phi$ is characterized in a matrix form of:

$$
N P V_{0}=\left[\begin{array}{l}
n p v_{01} \\
n p v_{02} \\
\cdots \\
n p v_{0 n}
\end{array}\right]
$$

Based on the discussion in the second section, operational premium can be decomposed into the operating efficiency of a company on particular assets and the strength of an enterprise's control over its assets. Hence, we build operating efficiency function $\left(E_{i}\right)$ and nonlinear shareholding-efficiency function $\left(f\left(w_{i}\right)\right)$ respectively.

\section{1) Operating efficiency function}

Given $E$ as the investor's efficiency space defined to be $E=\left[E_{1}, E_{2}, \cdots, E_{n}\right]$, where $E_{i}$ implies the investor's operating efficiencies of asset $i$. The matrix form of $E$ is written in:

$$
E=\left[\begin{array}{cccc}
1+e_{1} & & \ldots & \\
& 1+e_{2} & \ldots & \\
\ldots & \ldots & \ldots & \ldots \\
& & \ldots & 1+e_{n}
\end{array}\right]
$$

where $e_{i}$ indicates the value-added rate of project $i$ that a capital budgeter can achieve under $100 \%$ ownership. Meaning, if one E\&P project is owned by a professional investor, its value could be $n p v_{0 i}$, but if that asset is taken over by a capital budgeter, its value could be increased to $n p v_{0 i}\left(1+e_{i}\right)$, where $e_{i}$ is a constant and represents the valueadding capacity that a capital budgeter has because of his professional skills and management experience.

\section{2) Nonlinear shareholding-efficiency function}

For a specific investor, his operating efficiency for a certain asset is increasing at an accelerated speed with rising ownership interest. The nonlinear shareholding-efficiency function gauges the change of a capital budgeter's operational premium ratio. It is defined as follows:

$$
f=\left[\begin{array}{llll}
f\left(w_{1}\right) & & & \\
& f\left(w_{2}\right) & & \\
& & \ldots & \\
& & & f\left(w_{n}\right)
\end{array}\right]
$$

where $w_{i}$ indicates investor's ownership interest of asset $i$ in the portfolio space $\Phi$, and $w_{i} \in[0,100 \%] . f\left(w_{i}\right) \in[0,1], f(0)=0$, and $f(1)=1$. Besides, $f\left(w_{i}\right)$ is convex in $w_{i}$, hence, $\frac{\partial f\left(w_{i}\right)}{\partial w_{i}}>0$ and $\frac{\partial^{2} f\left(w_{i}\right)}{\partial w_{i}^{2}}>0$. 


\section{3) Operational premium function}

Assume one investor owns a royalty rate of $w_{i}$ on project $i$. When it comes to the professional investor, the value of the investment would be $w_{i} \times\left(n p v_{0 i}\right)$. While when it comes to the capital budgeter, the value of the investment would be:

$$
w_{i} \times n p v_{0 i}\left[1+e_{i} \times f\left(w_{i}\right)\right]
$$

For the whole asset portfolio $\Phi$, the operational premium vector is described by:

$$
\left[\begin{array}{c}
1+e_{1} \times f\left(w_{1}\right) \\
\cdots \\
\cdots
\end{array}\right.
$$

$$
\left.\begin{array}{ccc} 
& \ldots & \\
1+e_{2} \times f\left(w_{2}\right) & \ldots & \\
\ldots & \ldots & \ldots \\
& \ldots & 1+e_{n} \times f\left(w_{n}\right)
\end{array}\right]
$$

where $n p v_{i}$ indicates the anticipated revenue of the $i$ th project repurchased by the capital budgeter who is also the operator of that project, and $w_{i}$ represents the reallocated ownership interest of project $i$. The total wealth of reformed portfolio would be:

$$
\left[\begin{array}{llll}
w_{1} & w_{2} & \ldots & w_{n}
\end{array}\right]\left[\begin{array}{cccc}
1+e_{1} \times f\left(w_{1}\right) & & \ldots & \\
& 1+e_{2} \times f\left(w_{2}\right) & \ldots & \\
\ldots & \ldots & \ldots & \ldots \\
& & \ldots & 1+e_{n} \times f\left(w_{n}\right)
\end{array}\right]\left[\begin{array}{c}
n p v_{01} \\
n p v_{02} \\
\ldots \\
n p v_{0 n}
\end{array}\right]
$$

The risk constraint is subject to the original risk level $\delta^{2}$, and expressed as follows:

$$
\operatorname{Var}\left(\sum w_{i} \times n p v_{0 i} \times\left[1+e_{i} \times f\left(w_{i}\right)\right]\right) \leq \delta^{2}
$$

The budget constraint is defined by:

$$
\sum w_{i} E\left(n p v_{i}\right) \leq \text { Budget }
$$

Considering utility and efficiency coherently, we build the new objective function as follows:

$$
\begin{aligned}
& \operatorname{Max}\left\{E\left[u\left(\sum w_{i} \times n p v_{i}\right)\right]\right\}=-\exp \left\{-\left[\sum w_{i} \times n p v_{0 i}\left(1+e_{i} f\left(w_{i}\right)\right)\right] / R T\right\} \\
& \text { st. } \quad \operatorname{Var}\left(\sum w_{i} \times n p v_{0 i} \times\left[1+e_{i} \times f\left(w_{i}\right)\right]\right) \leq \delta^{2} \\
& \sum w_{i} E\left(n p v_{i}\right) \leq \text { Budget }
\end{aligned}
$$

where $\delta^{2}$ is the variance of the projects before optimization, and $n p v_{i}$ is the expected value of the repurchased projects for capital budgeter. $R T$ is short for "risk tolerance". $w_{i}, n p v_{0 i}, e_{i}$, and $f\left(w_{i}\right)$ are defined in Eqs. (3), (4) and (5).

\section{Simulation case study}

\subsection{Simulation assumptions}

Company A is a large multinational oil company in China. Taking the company's 19 under-development projects as the original portfolio, we use a Monte Carlo method to simulate the assets packet to find the utility-maximized portfolio. The main parameters of sampling are defined as follows:

Software: Crystal Ball 11.1

Stimulation frequency: 100,000 times

Value-driver variables: oil price, Capex, and Opex.

Variables described in Table 1.

\section{1) Oil price}

From the result of fitting Cushing oil future prices from Jan 2001 to December 2011, the oil prices obey the Beta distribution (where $\alpha=1.70, \beta=3.32$, Min $=\$ 11.54 / \mathrm{bbl}$, $\mathrm{Max}=\$ 152.39 / \mathrm{bbl}$ ); while according to the trend of oil prices in the first half of 2012, the oil prices can be considered to obey a different Beta distribution (where $\alpha=2, \beta=3$, Min $=\$ 40$ / bbl, Max $=\$ 160 / \mathrm{bbl})$.

\section{2) Capital expense (Capex)}

Assuming that the Capexes obey a lognormal distribution, the mean value is the expected value of the most likely scenario, and the standard deviation is $10 \%$ of that mean value. For example, in the basic scenario, the Capex is anticipated to be $\$ 632$ million. Capexes are assumed to subordinate to the lognormal distribution. Then, the mean value of that Capex is $\$ 632$ million and the standard deviation is 63.2 . 
Table 1 Proposed distribution of crucial variables

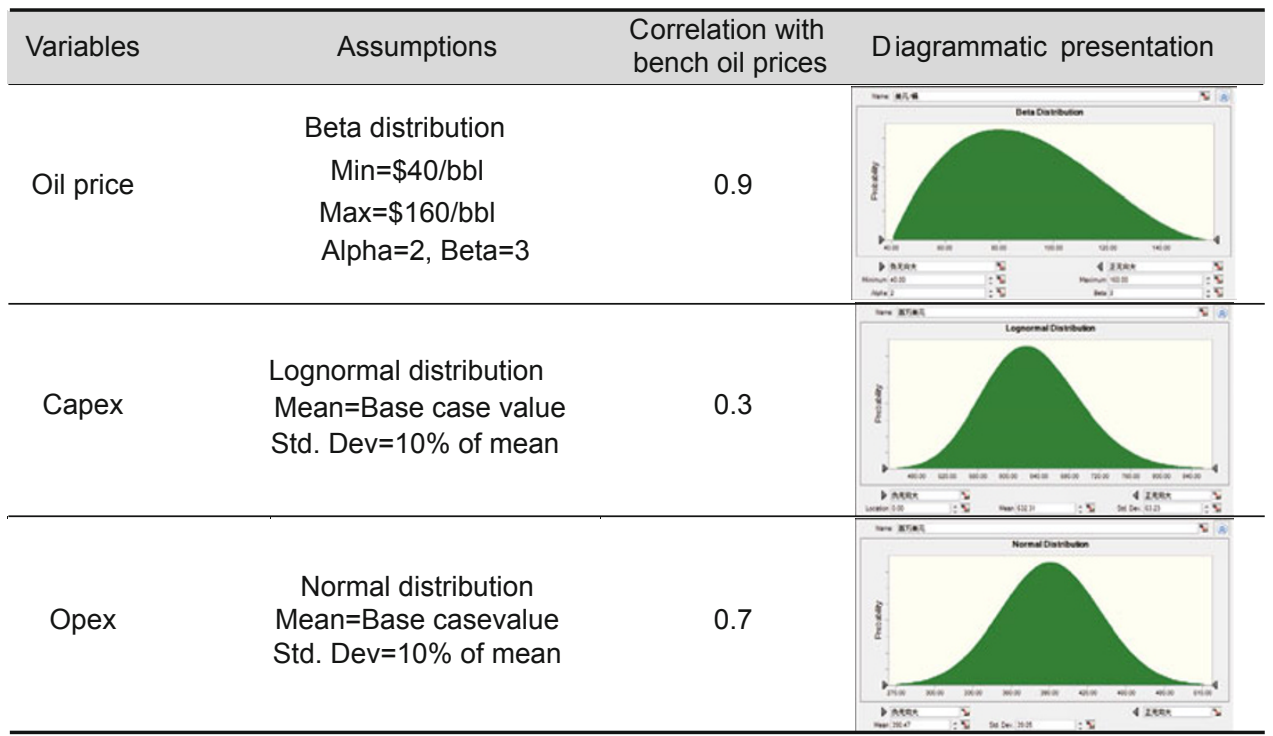

\section{3) Operating expense (Opex)}

Considering the Opexes to be normally distributed, the mean value is the anticipated value of the most possible scenario, and the standard deviation is $10 \%$ of that mean value. For instance, the Opex in the basic scenario is expected to be $\$ 390$ million, and Opexes are considered to be normally distributed. Thus, the mean value of that Opex is $\$ 390$ million, and the standard deviation is $10 \%$ of that mean value.

\section{4) Correlation of variables ${ }^{2}$}

The output of each project is irrelevant to each other, namely those productions are all independent of each other. For economic parameters, it assumes that the correlations are: If the yearly bench oil price is a variable, the correlation between the change of yearly sales price and the change of yearly bench price of each petroleum project is 0.9 ; the correlation between the change of yearly Capex and the change of yearly bench price of each project is 0.3 ; the correlation between the change of Opex and the change of bench price is 0.7 . Those figures are set according to the different relevant degrees between each economic parameter and bench price.

\subsection{Before portfolio optimization}

After taking $1 \times 10^{5}$ times of sampling simulation, the mean value of the asset packet without considering operational premium is $\$ 31,893$ million, the variance is $32,515,483$. Assuming the risk tolerance of investors to be $\$ 3000$ million, the anticipated utility of this portfolio bringing to investors calculated by Eq. (1) will be 4.24 .

Fig. 2 demonstrates the Mean NPV-variance space without considering operators' premium before optimization.

\footnotetext{
${ }^{2}$ To simplify the simulation procedures, the correlations between different parameters of different projects are not defined in this paper although those correlations are considered to exist. The correlations among parameters of different projects will be illustrated by using bench price.
}

The red curve indicates the optimal investment portfolios as demonstrated in Markowitz theory. Compared with the benchmark efficient frontier, at least three projects with variance higher than $1 \times 10^{7}$ can be optimized. These three projects locate in the inner space of the efficient frontier. Apparently, according to the risk-return boundary, the current assets allocation does not meet the optimized risk-return boundary (see Fig. 2), meaning it can be further optimized.

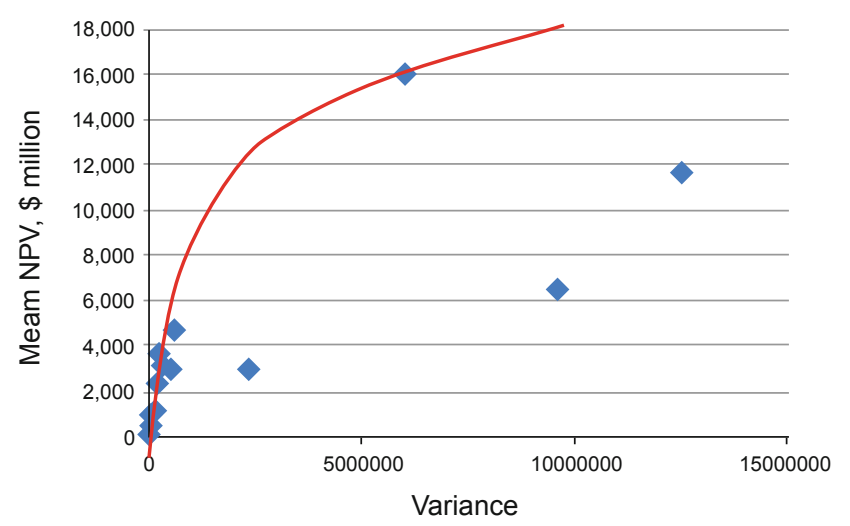

Fig. 2 Mean NPV-Variance space of assets without operational premium before optimization

\subsection{After portfolio optimization}

Based on the result of "before portfolio optimization" mentioned above, the utility-promotion process can be explained from the perspective of merger and acquisition:

In a simplified market, there are two investors: one is company A, a capital budgeter who specializes in oil and gas project operation, meaning he can put some premium on the asset after the acquisition; the other is a professional investor, who imposes no premium on purpose and whose behavior is completely market-oriented. In the 1 st step, company A sells all assets. The professional buyer will only bid for $\$ 31,893$ million, which in return becomes the budget ceiling 
of company A; in the 2nd step, company A reallocates the $\$ 31,893$ million to each of the 19 assets, then a new portfolio would be formed. Then we can reassess investors' new utilities. The target portfolio will be the utility-maximized portfolio under both the budget constraint of $\$ 31,893$ million and the risk constraint of $32,515,483$, and can be expressed as follows:

$$
\begin{aligned}
& \text { Budget } \leq W \cdot V \equiv 31893.31 \\
& \bar{W} \cdot \Omega \cdot \bar{W}^{T} \leq W \cdot \Omega \cdot W \equiv 32515483
\end{aligned}
$$

We perform numerical optimization simulation for a sampling frequency of 800 times to achieve stability (see Fig. $3)$.

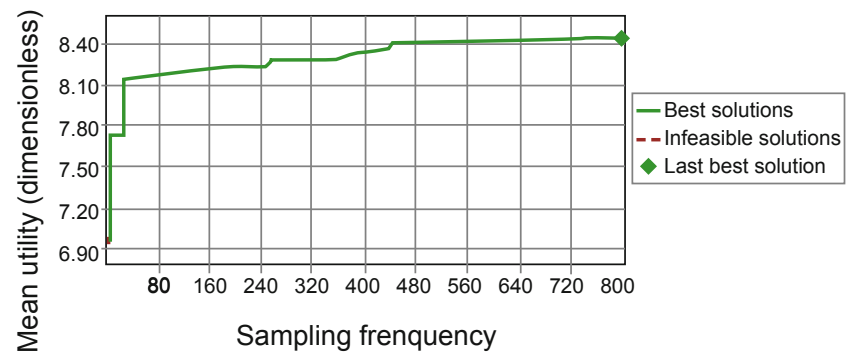

Fig. 3 Curve of numerical optimization simulation (Utility maximization) under a risk tolerance of $\$ 3000$ million (RT3000)

Based on the principle of utility maximization under budget constraint and risk constraint, the anticipated utility of the optimized portfolio almost doubled within the budget ( $\$ 31,893$ million) from 4.24 to 8.45 (see Fig. 4).

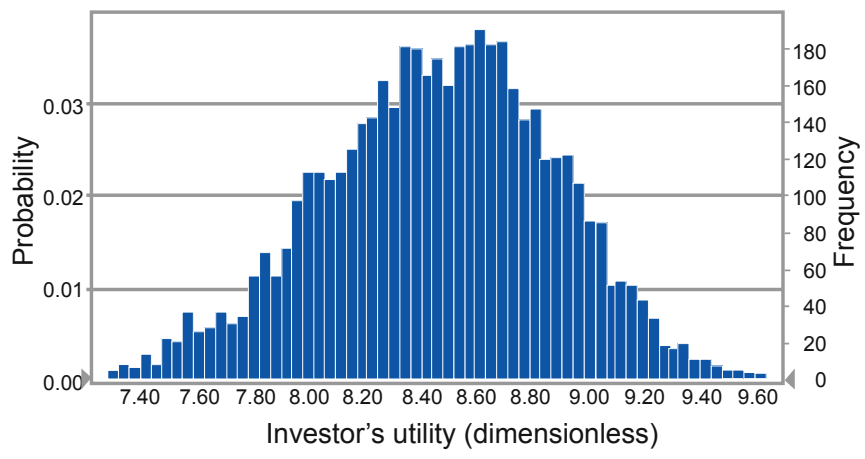

Fig. 4 Distribution of investor's utility after utility maximization under a risk tolerance of $\$ 3000$ million (RT3000)

Considering that different capital budgeters exhibit different levels of risk aversion, we recalculate simulations under three different risk tolerance levels, namely $\$ 30, \$ 300$, and $\$ 30,000$ million respectively, to improve the robustness. In these three experiments, we keep the optimization target, budget constraint and risk restriction constant. After $1 \times 10^{3}$ times of random simulation, the anticipated utility increases by $148 \%$ from 0.58 to 1.44 when risk tolerance rises to $\$ 30,000$ million, while $6.32 \%$ from 16.76 to 17.82 when risk tolerance declines to $\$ 30$ million. The simulation results reached stability are shown in Table 2 .
Table 2 Optimization results under different risk tolerances (RT)

\begin{tabular}{ccccc}
\hline $\begin{array}{c}\text { Optimization target } \\
\text { Budget constraint } \\
\text { Risk constraint }\end{array}$ & \multicolumn{5}{c}{$\begin{array}{c}\text { Maximize mean of utility } \\
\text { Variance }<=31,893 \text { million }\end{array}$} \\
\hline RT value (\$ million) & 30 & 300 & 3,000 & 30,000 \\
\hline $\begin{array}{c}\text { Anticipated utility } \\
\text { before optimization } \\
\text { Anticipated utility } \\
\text { after optimization }\end{array}$ & 16.76 & 11.49 & 4.24 & 0.58 \\
\hline $\begin{array}{c}\text { Variance of portfolio } \\
\text { after optimization }\end{array}$ & $18,962,757$ & $19,807,867$ & $17,887,355$ & $16,539,037$ \\
\hline
\end{tabular}

Table 2 shows that the variance of the portfolio under a set budget ceiling and risk constraint decreases sharply, and that the higher the risk tolerance level is, the more the anticipated utility increases. Namely, the utility of investors with higher risk tolerance has more room for improvement than that with lower risk tolerance.

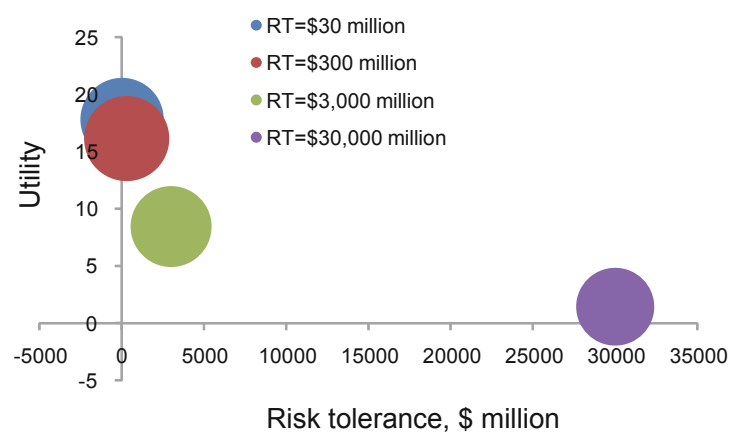

Fig. 5 Results of optimization considering risk appetite and operational premium

Fig. 5 shows the results of optimization considering risk appetite and operational premium, in which the horizontal axis represents risk tolerance level, the vertical axis shows the corresponding utility level (dimensionless) of each investor, and the size of the bubble indicates the variance of the portfolio after optimization. It can be seen that the anticipated utility decreases with increasing risk tolerance. This phenomenon is accordance with the nature of negative exponential utility function. The optimized investment plan is different with changing risk tolerances (See Fig. 6).

Fig. 6 shows the optimized choices for investors with various risk tolerance. At a risk tolerance of $\$ 30$ million, the optimal investment presents in a more centralized distribution (Fig. 6(a)), while at a risk tolerance of $\$ 30,000$ million, the optimal investment exhibits a more diversified distribution (Fig. 6(d)).

Fig. 6 shows that the allocation of the best portfolio is less centralized with growing risk tolerance, indicating that diversified strategy is positively correlated with investors' risk tolerance. Fig. 6 also shows that enterprise with lower risk tolerance would reduce their holdings of risky projects with high return, such as project 1 , project 9 , and project 10 . 


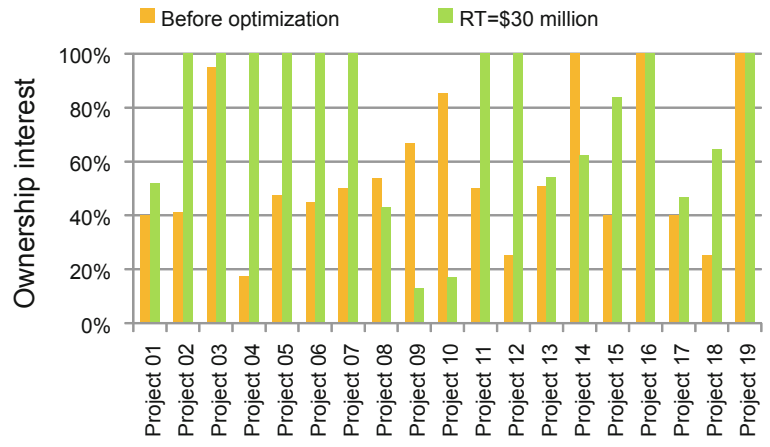

(a) $\mathrm{RT}=30$

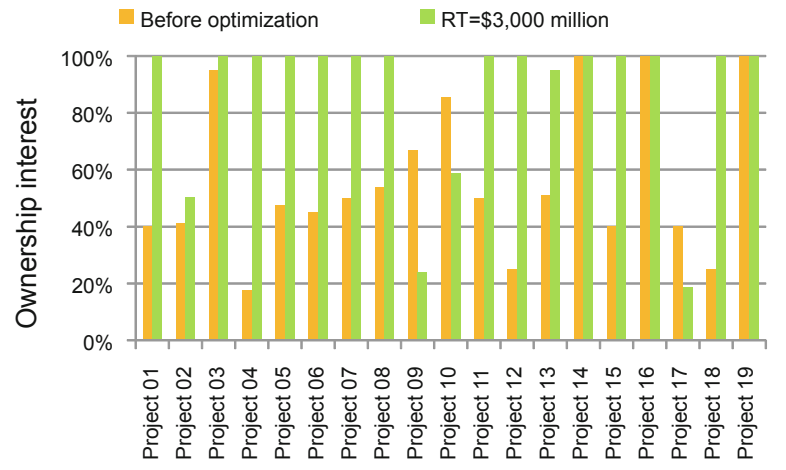

(c) $\mathrm{RT}=3000$

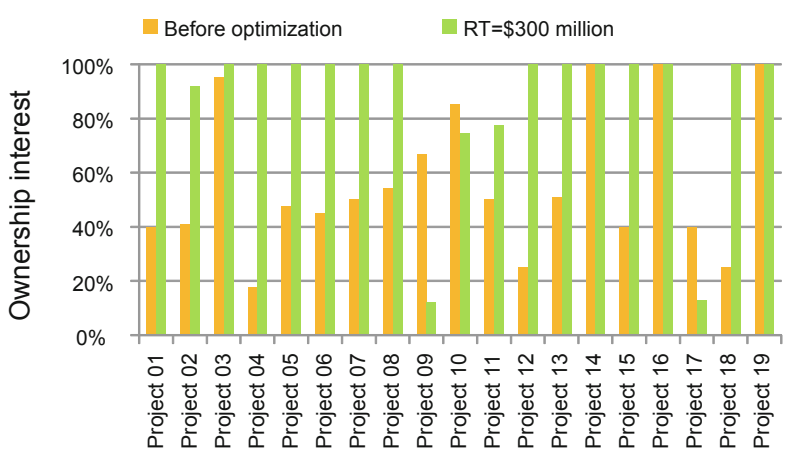

(b) $\mathrm{RT}=300$

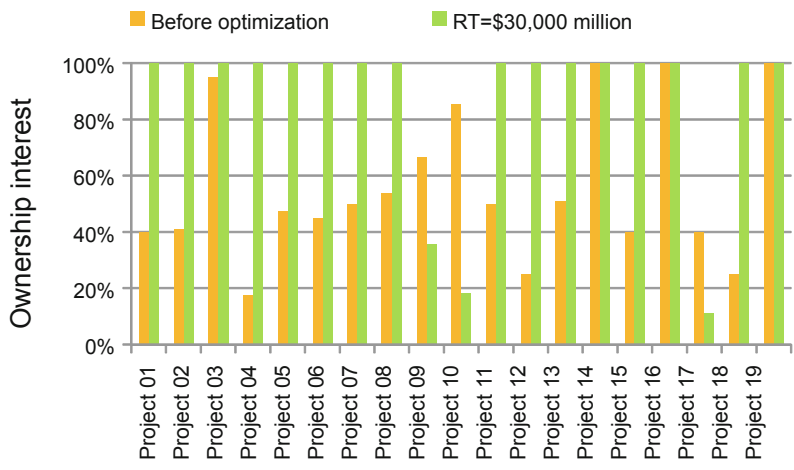

(d) RT=30000

Fig. 6 Optimized choices for investors with various risk tolerance

\section{Conclusions}

Although NPV is a deterministic indicator in most engineering dominant cultures, portfolio management is pushing it forward by considering investment opportunities from the view of capital budgeting. Based on Markowitz portfolio theory, this article built an improved portfolio selection model by introducing operational premium as a factor to distinguish the double identities of petroleum enterprises as both operators and investors. The concept of "operational premium" is borrowed from the concept of "acquisition premium". Since petroleum companies are not investors who gain profits by merely buying and selling those equities, they also act as project operators who should accomplish the production targets, improve the petroleum production and recover the investment. Therefore, those companies can generate a "operational premium" by using techniques, production and management experience and inner capital markets to save costs and increase returns. According to actual production experiences, the size of operational premium can be influenced by the control ability of one petroleum company on its projects or assets: if the equity ratio of one petroleum company in one project rises, the operational premium would increase gradually at a growing speed.

We used numerical simulation of real data from 19 under-development projects to further analyze the effect of operational premium and risk tolerance on the optimization results. The numerical simulation results shows operational premium has significant impact on asset selection:

1) After a Monte Carlo simulation of the improved portfolio selection model, the expected utility of the company's present portfolio increased dramatically, and the risk represented by portfolio variance has been decreased sharply;

2) Concerning operational premium, the optimization result suggests holding high ratio of assets with high operational premium and low ratio of assets with low operational premium;

3) The utility of investors with higher risk tolerance has more room for improvement than the utility with lower risk tolerance;

4) Diversification strategy is positively correlated with investors' risk tolerance. Investors with a higher degree of risk aversion would choose intensively centralized portfolios.

\section{Acknowledgements}

The authors are grateful for financial support from National Science and Technology Major Project of the Ministry of Science and Technology of China "Research on Investment estimation tools and economic appraisal system integration and development" (2011ZX05030-006-04).

\section{References}

Arnesano M, Carlucci A P and Laforgia D. Extension of portfolio theory application to energy planning problem-The Italian case. Energy. 2012. 39(1): 112-124

Ball B C and Savage S L. Notes on exploration and production portfolio optimization. working paper. 1999. Available at: http://archive.ite. journal.informs.org/Vol1No2/Savage/Notes.pdf

Cartwright G L. Application of Markowitz portfolio theory in the oil and gas industry. Oil \& Gas Financial Journal. 1 September 2011. 1-13 
Cozzolino J M. Management of Oil and Gas Exploration Risk. West Berlin, New Jersey: Cozzolino Associates. 1977

Cozzolino J M. Controlling risk in capital budgeting: A practical use of utility theory for measurement and control of petroleum exploration risk. The Engineering Economist: A Journal Devoted to the Problems of Capital Investment. 1979. 25(3): 161-186

Deng S J and Xu L. Mean-risk efficient portfolio analysis of demand response and supply resources. Energy. 2009. 34(10): 1523-1529

Egozcue M L, García F, Wong W K et al. Do investors like to diversify? A study of Markowitz preferences. European Journal of Operational Research. 2011. Available at: http://works.bepress.com/martin egozcue/1

Erdogan M and Mudford B. Optimization of decision tree and simulation of portfolios: a comparison. SPE Hydrocarbon Economics and Evaluation Symposium, 2-3 April 2001, Dallas, Texas, U.S.A. (SPE 68575)

Evans R, Moran C J and Brereton D. Beyond NPV-A review of valuation methodologies and their applicability to water in mining. Proceedings of the Water in Mining 2006 Conference, Melbourne, 2006: 97-103. Available at: http://www.csrm.uq.edu.au/ publications/158-beyond-npv-a-review-of-valuation-methodologiesand-their-applicability-to-water-in-mining

Fisher I. The Nature of Capital and Income. New York: Macmillan. 1906

Guerrero-Lemus R. Marrero G A and Puch L A. Costs for conventional and renewable fuels and electricity in the worldwide transport sector: A mean-variance portfolio approach. Energy. 2012. 44(1): 178-188

Guo Q L. A portfolio optimization model for petroleum exploration projects with consideration of geological risk. Petroleum Exploration and Development. 2007. 34(6): 760-764 (in Chinese)

Hayashib S H D, Ligeroa E L and Schiozera D J. Risk mitigation in petroleum field development by modular implantation. Journal of Petroleum Science and Engineering. 2010. 75(1-2): 105-113

Huanga Y H and Wub J H. A portfolio risk analysis on electricity supply planning. Energy Policy. 2008. 36(2): 627-641

Jafarizadeh B. Financial factor models for correlated inputs in the simulation of project cash flows. Journal of Petroleum Science and Engineering. 2010. 75(1-2): 54-57

Jordanger I and Klakegg O J. Value management beyond earned value. PM World Journal. 2013. 2(2). Available at http://pmworldlibrary. net/wp-content/uploads/2013/03/pmwj7-feb2013-jordanger-klakeggvalue-management-beyond-earned-value-second-edition.pdf

Lasdon L S, Faya L C, Lake L W, et al. Constructing oil exploration and development project portfolios using several risk measuresa realistic example. Hydrocarbon Economics and Evaluation Symposium, 1-3 April 2007, Dallas, Texas, U.S.A. (SPE 107708)

Lima G A, Suslick S B, Quintão P J. Portfolio optimization of oil production projects using mathematical programming and utility theory. 18th International Congress of Mechanical Engineering by ABCM, 6-11 November 2005, Ouro Preto, MG

Liu M M, Wang Z, Zhao L, et al. Production sharing contract: An analysis based on an oil price stochastic process. Petroleum Science. 2012. 9(3): 408-415

Locatelli G and Mancini M. Large and small baseload power plants: Drivers to define the optimal portfolios. Energy Policy. 2011. 39(12): 7762-7775

Mansoor H A-H. Utility efficient frontier: an application in the oil and gas industry. Natural Resources Research. 2007. 16(4): 305-312

Markowitz H. Portfolio Selection. Journal of Finance. 1952. 7(1): 77-91

Markowitz H. Portfolio selection: Efficient Diversification of Investment. New York: John Wiley \& Sons. 1959

Orman M M and Duggan T E. Applying modern portfolio theory to upstream investment decision making. Society of Petroleum Engineers. 1999. 51(3): 50-53

Park C, Kang J M and Ahn T. A stochastic approach for integrating market and technical uncertainties in economic evaluations of petroleum development. Petroleum Science. 2009. 6(3): 319-326

Quiek A N. Exploration strategy: An integral part of strategic planning. Oil and Gas Journal. 1982(9): 286-300

Quiek A N and Buek N A. Strategic Planning for Exploration Management. Boston: International Human Resources Development Corp. 1983: 161-162

Rahmawatia S D, Whitson C H, Foss B, et al. Integrated field operation and optimization. Journal of Petroleum Science and Engineering. 2012. 81(1): 161-170

Sáncheza F and Al-Harthy M H. Risk analysis: Casing-while-drilling (CwD) and modeling approach. Journal of Petroleum Science and Engineering. 2011. 78(1): 1-5

Shu S B, Zeithammer U R and Payne U J. Consumer preferences for annuities: Beyond NPV. Working Paper. 2013

Tobin J. Fisher's the nature of capital and income. American Journal of Economics and Sociology. 2005. 64(1): 207-214

Vithayasrichareon P and MacGill I F. Portfolio assessments for future generation investment in newly industrializing countries-A case study of Thailand. Energy. 2012. 44(1): 1044-1058

Walls M R and Dyer J S. Risk propensity and firm performance: A study of the petroleum exploration industry. Management Science. 1996. 42(7): 1004-1021

Walls M R. Combining decision analysis and portfolio management to improve project selection in the exploration and production firm. Journal of Petroleum Science and Engineering. 2004. 44(1-2): 55-65

Wang $\mathrm{Z}$ and Wang $\mathrm{K}$. Investment decisions in oil \& gas exploration and development based on Markowitz's Portfolio Selection Theory. Journal of China University of Petroleum (Edition of Natural Science). 2008. 32(1):152-155 (in Chinese)

Ward K and Ryals L. Latest thinking on attaching a financial value to marketing strategy: Through brands to valuing relationships. Journal of Targeting, Measurement and Analysis for Marketing. 2001. 9: $327-340$

Westner G and Madlener R. Development of cogeneration in Germany: A mean-variance portfolio analysis of individual technology's prospects in view of the new regulatory framework. Energy. 2011. 36(8): 5301-5313

Willigers B J A, Weis F and Majou F. Creating portfolio insights by a practical multi-method optimization approach. SPE Annual Technical Conference and Exhibition, 30 October-2 November 2011, Denver, Colorado, U.S.A. (SPE 146583)

$\mathrm{Xu}$ J. Beyond expected value: integrated project valuation for decision making under uncertainty. In 75th EAGE Conference \& Exhibition incorporating SPE EUROPEC 2013. Jun 12-13, 2013, London, UK

Zhang B S and Wang Q. Analysis and forecasts of investment scale and structure in upstream sector for oil companies based on system dynamics. Petroleum Science. 2011. 8(1): 120-126

Zhang J, Sun Z D, Zhang Y W, et al. Risk-opportunity analyses and production peak forecasting on world conventional oil and gas perspectives. Petroleum Science. 2010. 7(1): 136-146

Zhao D. The Study on CNPC's Oversea Oil and Gas Assets Portfolio Optimization: Dissertation submitted to China University of Petroleum, Beijing, for the degree of Doctor of Engineering. April. 2010 (in Chinese)

Zhu L and Fan Y. Optimization of China's generating portfolio and policy implications based on portfolio theory. Energy. 2010. 35(3): 1391-1402

(Edited by Zhu Xiuqin) 